\title{
How to perform Contrast-Enhanced Ultrasound (CEUS)
}

\section{()(1) ( $\odot \ominus$}

Authors

Christoph F. Dietrich', Michalakis Averkiou², Michael Bachmann Nielsen³, Richard G. Barr ${ }^{4}$, Peter N. Burns ${ }^{5}$, Fabrizio Calliada ${ }^{6}$, Vito Cantisani ${ }^{7}$, Byung Choi ${ }^{8}$, Maria C. Chammas ${ }^{9}$, Dirk-André Clevert ${ }^{10}$, Michel Claudon ${ }^{11}$, Jean-Michel Correas ${ }^{12}$, Xin-Wu Cui ${ }^{13}$, David Cosgrove ${ }^{14}$, Mirko D'Onofrio ${ }^{15}$, Yi Dong ${ }^{16}$, John R. Eisenbrey ${ }^{17}$, Teresa Fontanilla ${ }^{18}$, Odd Helge Gilja ${ }^{19}$, Andre Ignee ${ }^{13}$, Christian Jenssen ${ }^{20}$, Yuko Kono ${ }^{21}$, Masatoshi Kudo ${ }^{22}$, Nathalie Lassau ${ }^{23}$, Andrej Lyshchik ${ }^{17}$, Maria Franca Meloni ${ }^{24}$, Fuminori Moriyasu ${ }^{25}$, Christian Nolsøe ${ }^{26}$, Fabio Piscaglia27, Maija Radzina28, Adrian Saftoiu29, Paul S. Sidhu³ ${ }^{30}$, loan Sporea ${ }^{31}$, Dagmar Schreiber-Dietrich ${ }^{32}$, Claude B. Sirlin ${ }^{33}$, Maria Stanczak ${ }^{17}$, Hans-Peter Weskott ${ }^{34}$, Stephanie R. Wilson ${ }^{35}$, Juergen Karl Willmann ${ }^{36}$, Tae Kyoung Kim ${ }^{37}$, Hyun-Jung Jang ${ }^{37}$, Alexandar Vezeridis ${ }^{38}$, Sue Westerway ${ }^{39}$

\section{Affiliations}

1 Caritas-Krankenhaus, Medizinische Klinik 2, Bad Mergentheim, Germany and Ultrasound Department, The First Affiliated Hospital of Zhengzhou University, Zhengzhou, China

2 Bioengineering, University of Washington, Seattle, United States

3 Rigshospitalet, Dep. of Radiology, Copenhagen, Denmark

4 Radiology, Northeastern Ohio Medical University, Rootstown, United States

5 Dept Medical Biophysics, University of Toronto. Sunnybrook Research Institute, Toronto, Canada

6 Policlinico San Matteo, University of Pavia, Department of Radiology, Pavia, Italy

7 Department of Radiology, "Sapienza" University of Rome, ROME, Italy

8 Department of Radiology, Chung-Ang University Hosptial, Seoul, Korea (the Republic of)

9 Hospital das Clínicas da Faculdade de Medicina da Universidade de São Paulo, Instituto de Radiologia, São Paulo, Brazil

10 Department of Clinical Radiology, University of Munich-Grosshadern Campus, Munich, Germany

11 Department of Pediatric Radiology, Centre Hospitalier Universitaire de Nancy and Université de Lorraine, Vandoeuvre, France

12 Hopital universitaire Necker-Enfants malades, Service de Radiologie Adultes, Paris, France

13 Department of Medical Ultrasound, Tongji Hospital of Tongji Medical college, Huahzong University of Science and technology, Wuhan, China

14 Imperial College London, Imaging, London, United Kingdom of Great Britain and Northern Ireland

15 Radiology, University of Verona, Verona, Italy

16 Department of Ultrasound, Zhongshan Hospital, Fudan University, 200032 Shanghai, China

17 Department of Radiology, Thomas Jefferson University, Philadelphia, United States

18 Radiology, Hospital Universitario Puerta del Hierro Majadahonda, Majadahonda, Spain
19 National Centre for Ultrasound in Gastroenterology, Haukeland University Hospital, Bergen and Department of Clinical Medicine, University of Bergen, Norway

20 Krankenhaus Märkisch Oderland Strausberg/ Wriezen, Klinik für Innere Medizin, Wriezen, Germany

21 Department of Medicine and Radiology, University of California, San Diego, United States

22 Kinki Daigaku Igakubu, Department Gastroenterology and Hepatology, Osakasayama, Osaka, Japan

23 Gustave Roussy and IR4MUMR8081. Université Paris-Sud, Université Paris-Saclay, Radiology, Paris, France

24 Radiology Department of Interventional Ultrasound - Casa di cura Igea- Milano, Italy

25 Sanno Hospital,International University of Helth and Welfare, Center for Cancer Ablation Therapy, Tokyo, Japan

26 Ultrasound Section, Division of Surgery, Dep. of Gastroenterology, Herlev Hospital Copenhagen Academy for Medical Education and Simulation (CAMES), University of Copenhagen, Denmark

27 Div. Internal Medicine, Dept of Medical and Surgical Sciences, Bologna, Italy

28 P.Stradina Clinical University Hospital, Diagnosic Radiology Institute, Riga, Latvia

29 Research Center of Gastroenterology and Hepatology, University of Medicine and Pharmacy of Craiova, Craiova, Romania

30 King's College London, Radiology, London, United Kingdom of Great Britain and Northern Ireland

31 Gastroenterology, University of Medicine and Pharmacy Timisoara, Timisoara, Romania

32 Cariats-Krankenhaus Bad Mergentheim, Pediatrics, Bad Mergentheim, Germany

33 Liver Imaging Grup, University of California, Department of Radiology, San Diego, United States

34 Klinikum Siloah, Ultrasound Outpatient Department, Hannover, Germany

35 Department of Radiology, Foothills Medical Centre University of Calgary, Division of Ultrasound, Calgary, Canada

36 Department of Radiology, Stanford University, Stanford, United States 


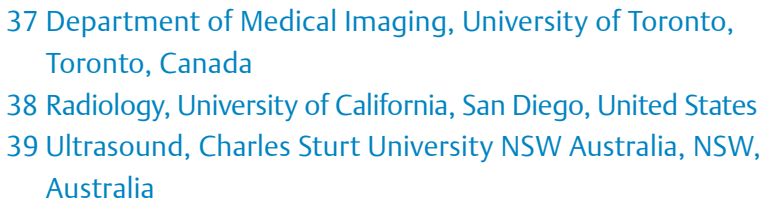

Key words

guidelines, teaching, ultrasonography, cancer

received 25.09.2017

revised 27.11.2017

accepted 29.11.2017

Bibliography

DOI https://doi.org/10.1055/s-0043-123931

Ultrasound Int Open 2017; 3: E2-E15

(c) Georg Thieme Verlag KG Stuttgart · New York

ISSN 2199-7152

Correspondence

Dr. Christoph Dietrich, MD

Caritas-Krankenhaus
Medizinische Klinik 2

Uhlandstr. 7

Bad Mergentheim, 97980

Germany

Tel.: +49/7931/58 2201, Fax: +49/7931/58 2290

Christoph.Dietrich@ckbm.de

\section{ABSTRACT}

"How to perform contrast-enhanced ultrasound (CEUS)" provides general advice on the use of ultrasound contrast agents (UCAs) for clinical decision-making and reviews technical parameters for optimal CEUS performance. CEUS techniques vary between centers, therefore, experts from EFSUMB, WFUMB and from the CEUS LI-RADS working group created a discussion forum to standardize the CEUS examination technique according to published evidence and best personal experience. The goal is to standardise the use and administration of UCAs to facilitate correct diagnoses and ultimately to improve the management and outcomes of patients.

\section{Introduction}

\section{An introduction to terminology}

The acronym CEUS refers to contrast-enhanced ultrasound techniques in general [1-11]. Dynamic contrast enhanced ultrasound (DCE-US) refers to quantitative time intensity curve (TIC) analysis [11-13] using either bolus injection of microbubbles [13-16] or intravenous infusion with disruption-replenishment technique [17] which are used for treatment response evaluation in oncology [18] and for activity assessment in inflammation of the bowel wall in inflammatory bowel disease [19-22]. 3D CEUS refers to image acquisition of data volumes. Introduced in 2002 [9], 3D CEUS is available in certain systems but it is still under investigation [23-26].

\section{CEUS phases}

CEUS allows real-time recording and evaluation of the wash-in and wash-out phases of the ultrasound contrast agent (UCA) over several minutes. When examining the liver, this provides dynamic visualisation of different vascular phases. Owing to the specific supply of blood to the liver three different phases have been defined: the arterial (AP), the portal venous (PVP), and the late (sinusoidal) phases (LP) [27, 28].

All clinically approved microbubbles, regardless of whether they are reticuloendothelial or purely blood pool, can easily be destroyed by ultrasound energy. This occurs most often by excessive or continuous scanning in a single plane, though it may also occur if the acoustic power is changed from the recommended value (typically less than $1 \%$ ) to a higher acoustic power. Once the shell is disrupted, the gas from the microbubbles diffuses, and microbubbles lose their scattering properties and are no longer effective contrast agents. Microbubble destruction, therefore, results in time- and depth-dependent loss of contrast, which not only reduces image quality but can also lead to spurious signal loss that may mimic le- sion washout. Reducing microbubble destruction is therefore important. Using optimal low MI settings reduces microbubble destruction to a minimal level. A useful sequence is to scan continuously and record a cine loop from the earliest arrival of the microbubbles to include the peak of arterial enhancement, and up to $60 \mathrm{~s}$. Thereafter scanning should be intermittent, with storage of single images or short loops at about 30-60 s intervals to show the presence of washout.

The main diagnostic features are:

1. Vascular architecture (evaluated in the early wash-in phase).

2. Contrast enhancement of the lesion compared to the adjacent tissue (time course of wash-in and wash-out).

The combined evaluation of above diagnostic features makes it possible to characterize focal liver lesions (FLL) in healthy parenchyma [29-32] as malignant - Fig. 1 or benign > Fig. 2 .

The combined evaluation of the above diagnostic features makes it possible to characterize focal liver lesions (FLL) in patients with liver cirrhosis as typical for HCC according to the LI-RADS system (see below) [33-36].

Some contrast agents (such as Sonazoid ${ }^{T M}$, BR14, BR38) are phagocytosed by cells of the mononuclear phagocyte system (reticulo-endothelium, e.g., Kupffer cells in the liver). Phagocytosis may start as early as the arterial phase and becomes pronounced in the late phase. This results in accelerated clearance of the agents from the vascular distribution volume [37]. These UCAs persist significantly longer in the liver parenchyma than purely vascular agents so that a fourth phase, the post-vascular phase (also known as the Kupffer cell phase), can be defined. For these reasons, transit times and time intensity curves (TIC) differ for purely blood pool versus reticuloendothelial UCAs. The latter should not be used to evaluate hepatic transit times, as they do not reflect the hepatic kinetics. 

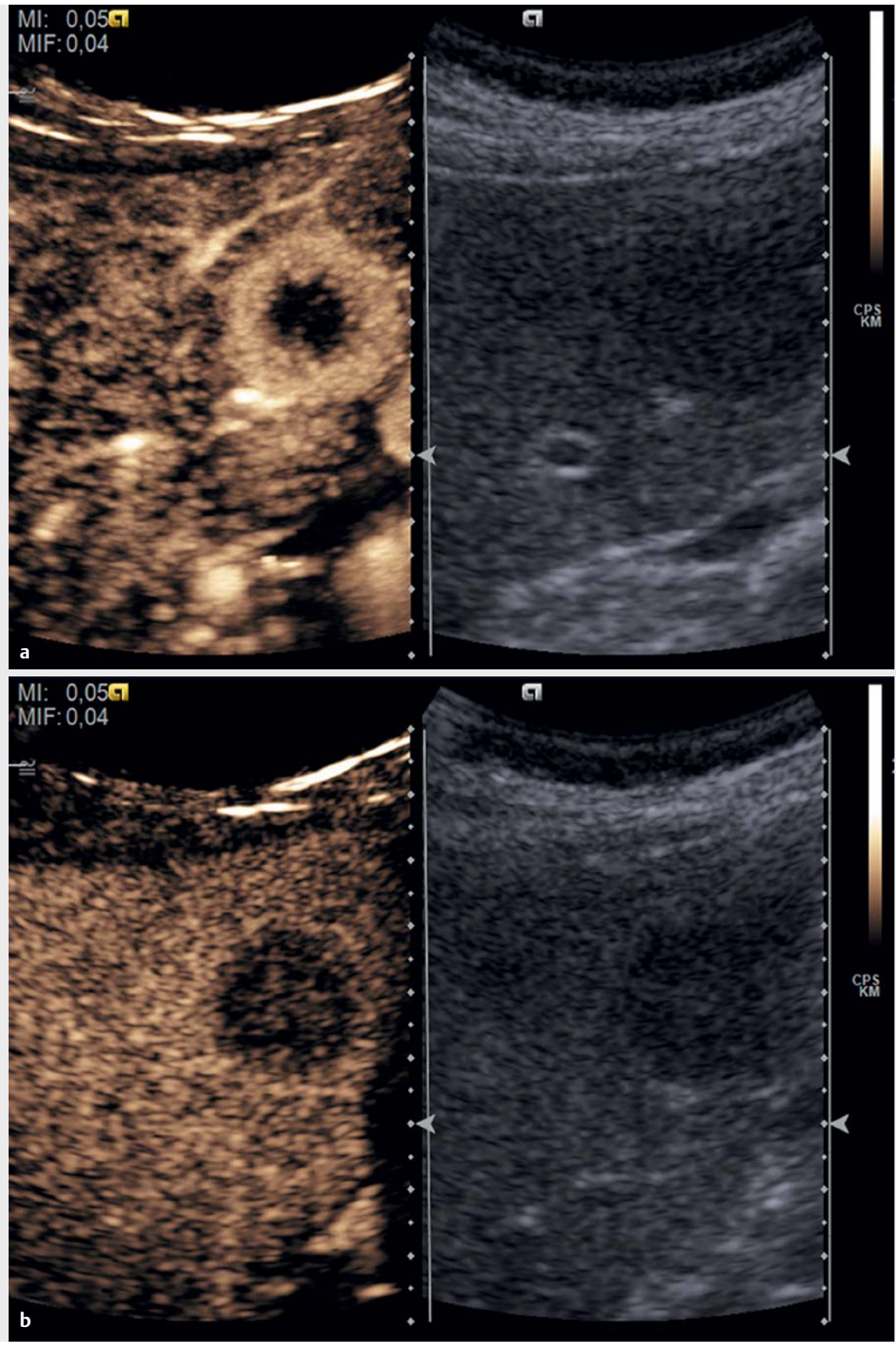

- Fig. 1 Malignant focal liver lesions in healthy liver parenchyma show a variable arterial enhancement pattern according to their etiology (rim enhancement in the case of some metastases a and as decisive criteria hypoenhancement in the portal venous (sinusoidal and "liver specific") phase in comparison to the surrounding liver parenchyma $\mathbf{b}$.

\section{Enhancement (degree and timing)}

The contrast behaviour of a lesion or region of interest in the liver described in terms of the degree (relative to the adjacent parenchyma) and timing (phase) of enhancement is discussed in $[4,38]$. It is important to know in advance if the liver is healthy or diseased (e.g, liver cirrhosis, fibrosis or steatosis). This may affect the contrast behavior of the lesion and liver parenchyma as well.

Enhancement refers to the intensity of the signal relative to the adjacent parenchyma as isoenhancing, hyperenhancing and hypoenhancing. Sustained enhancement refers to continuation of the same or greater intensity of enhancement in the lesion relative to the adjacent parenchyma over time. It applies to lesions that are iso- or hyperenhancing in the arterial phase. Complete absence of enhancement can be described as non-enhancing $[4,38,39]$.

Describing the degree of enhancement is preferred although some authors designate the degree of vascularity of a region relative to adjacent liver as hypervascular, isovascular, hypovascular. The term "vascular" may be incorrect from a histologic, as well as physiologic, point of view. It should be clarified that imaging major vessels, likewise by Doppler technique, is defined as vascularization. 

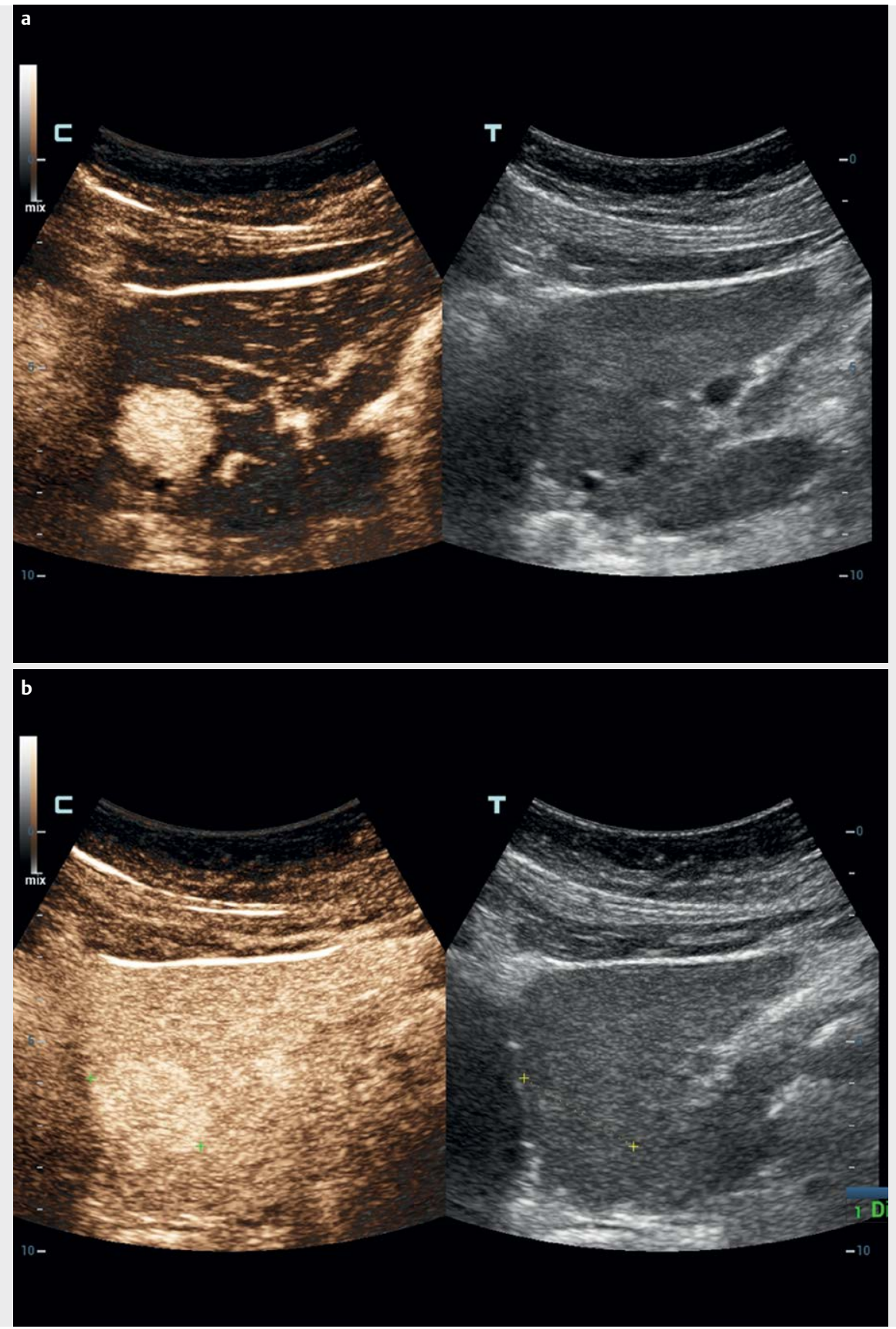

- Fig. 2 Benign focal liver lesions in healthy liver parenchyma show a variable arterial enhancement pattern according to their etiology a and as decisive criteria iso- or hyper-enhancement in the portal venous (sinusoidal and "liver specific") phase in comparison to the surrounding liver parenchyma b.

The definition of perfusion is "volume of blood per time per mass of tissue" (unit: $\mathrm{ml} / \mathrm{min} / \mathrm{g}$ tissue)". To know this is relevant for tissues with volume pulsation (e. g., the myocardium). By using CEUS, both vascularization and relative perfusion can be imaged. Both terms are sometimes used interchangeably without clarification.

The enhancement pattern should be described separately for the different phases discussed above. Conventional, but imprecise time points separate these different phases (see also "contrast phases of enhancement") [40]. By convention, however, the timing of events on CEUS is routinely recorded by its actual time in seconds as shown on a visible timer on the scanner screen.

\section{"Wash-in" and "wash-out"}

"Wash-in", used for both qualitative and quantitative analyses, refers to the progressive enhancement within a region of interest from the arrival of microbubbles in the field of view, to "peak enhancement", and "wash-out" to the reduction in enhancement which follows peak enhancement $[4,38]$. As explained above, the timing (early versus late onset, fast versus slow), degree (complete, incomplete) and pattern should be described in comparison to the surrounding "normal" parenchyma. The characteristic features of a TIC analysis are shown in ₹ Fig. $3[11,41]$. This model for quantification of tumor vascularization was applied in multicentric studies validating the AUC as predictive marker $[42,43]$. 


\section{Imaging mode}

Only machines that offer nonlinear imaging modes designed for contrast imaging should be used. Where there is a choice of modes, those designed for low MI abdominal scanning should be selected. While in these modes, settings like "high resolution" or "penetration" are often available. These change a host of parameters together and can help adjust the scanner when optimizing a particular examination. These settings should be tried before attempting to adjust the MI or the dose of agent (see below). Once in a low MI contrast mode and the agent is in the patient, reverting to a non-contrast mode will immediately raise the $\mathrm{MI}$ and destroy the agent. This should therefore be avoided.

\section{Choice of transducer}

Transducers that have specific CEUS optimized settings are recommended. For liver imaging, curvilinear arrays are preferred for most cases. Linear probes with higher transmit frequencies may be useful in cases of superficial lesions and when more spatial resolution is necessary. In this case, higher contrast doses may be beneficial (e. g., thyroid, breast, lymph nodes, prostate), as the agents become less efficient nonlinear scatterers at higher frequencies.

\section{Image depth consideration}

Typically, at low MI FLL up to $12-15 \mathrm{~cm}$ in depth can be imaged. At larger depths (and depending on the system used, and the patient's condition, e. g., cirrhosis) it may be difficult to visualize lesions. Lower transmit frequency can be selected using the same transducer or lower frequency transducers allowing better penetration with the disadvantage of lower spatial resolution, eventually resulting in suboptimal imaging of small superficially located lesions. Increasing the MI may improve penetration but at the expense of microbubble destruction especially in the nearfield. In general, where there is a choice of amplitude or power modulation imaging modes, these will have better depth penetration (though somewhat poorer resolution) than pure pulse inversion modes.

\section{Focus}

The focus should be positioned just deep to the target lesion for most ultrasound scanners [44]. Deeper focal zones might be used to achieve a more uniform acoustic field, which improves sensitivity to the agents and lessens the risk of bubble disruption. Other focus positions have been proposed for quantification studies [45].

\section{Gain}

Gain refers to the received signal amplification. For CEUS the gain usually is set very slightly above the noise floor so that before microbubbles arrive, the image is dark and with a "hint" (very low level) of noise. If the gain is set too low (image starts out too dark), weak microbubble signals are not detected and only signals from larger vessels are recorded. If the gain is set too high (image starts out bright and grainy even before the microbubbles arrive) the received echoes from the bubbles are clipped after a certain amplitude (signal saturation > Fig. 4).

Acoustic shadowing is the depth-dependent reduction in ultrasound amplitude due to excessive scattering from microbubbles. The nearfield microbubbles obscure and "shadow" the far field ones. Acoustic shadowing is due to excessive dose of UCA or in-

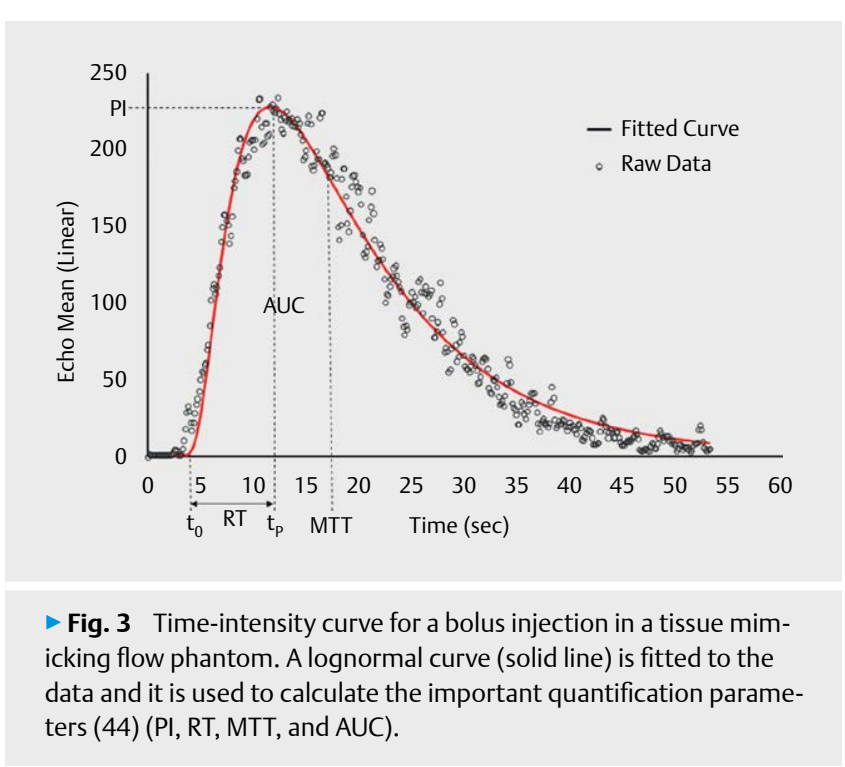

creased microbubble concentration. The UCA dose should be adapted to the patient and the clinical indication. CEUS is always performed with low MI to avoid bubble destruction and harmonic signal generation from tissues. Typically, modern high-end diagnostic ultrasound scanners should effectively suppress tissue signals at low Ml's over the entire depth to enhance the visualization of microbubbles.

\section{Background signal (noise)}

The use of a dual-image display format is essential in CEUS studies and it is recommended especially in examining small lesions. In this display format, a conventional B-mode low MI fundamental image and a bubble-only contrast image are displayed side-by-side. The reason this is useful is that the nonlinear image is almost completely black (before contrast administration and under ideal conditions) making it difficult to keep the lesion of interest in the image plane. Having the conventional image displayed simultaneously allows the operator to keep the lesion in the imaging plane. Using the B-mode image for guidance, place calipers on the target lesion on both screens simultaneously to facilitate enhancement characterization. It is also possible to overlay the contrast and low MI fundamental B-mode plane image. For quantitative studies, it is critical to maintain the transducer at the same place and avoid motion. Pronounced hyperechoic lesions may still be visible on the contrast image before the arrival of the agent. TIC will help to better define the wash-out characteristics in these cases. It should be noted that in most systems, the quality of the B-mode image in dual-image displays is inferior to that obtained with the same settings in non-contrast mode.

\section{Dynamic range}

The compression or dynamic range of the ultrasound system also plays a key role in microbubble visualization. A small dynamic range is preferred in cases of very low signal and a wide dynamic range is preferred when the objective is to perform quantification (to avoid signal saturation). The dynamic range should be set to optimise the expected enhancement pattern. The dynamic range is the range 


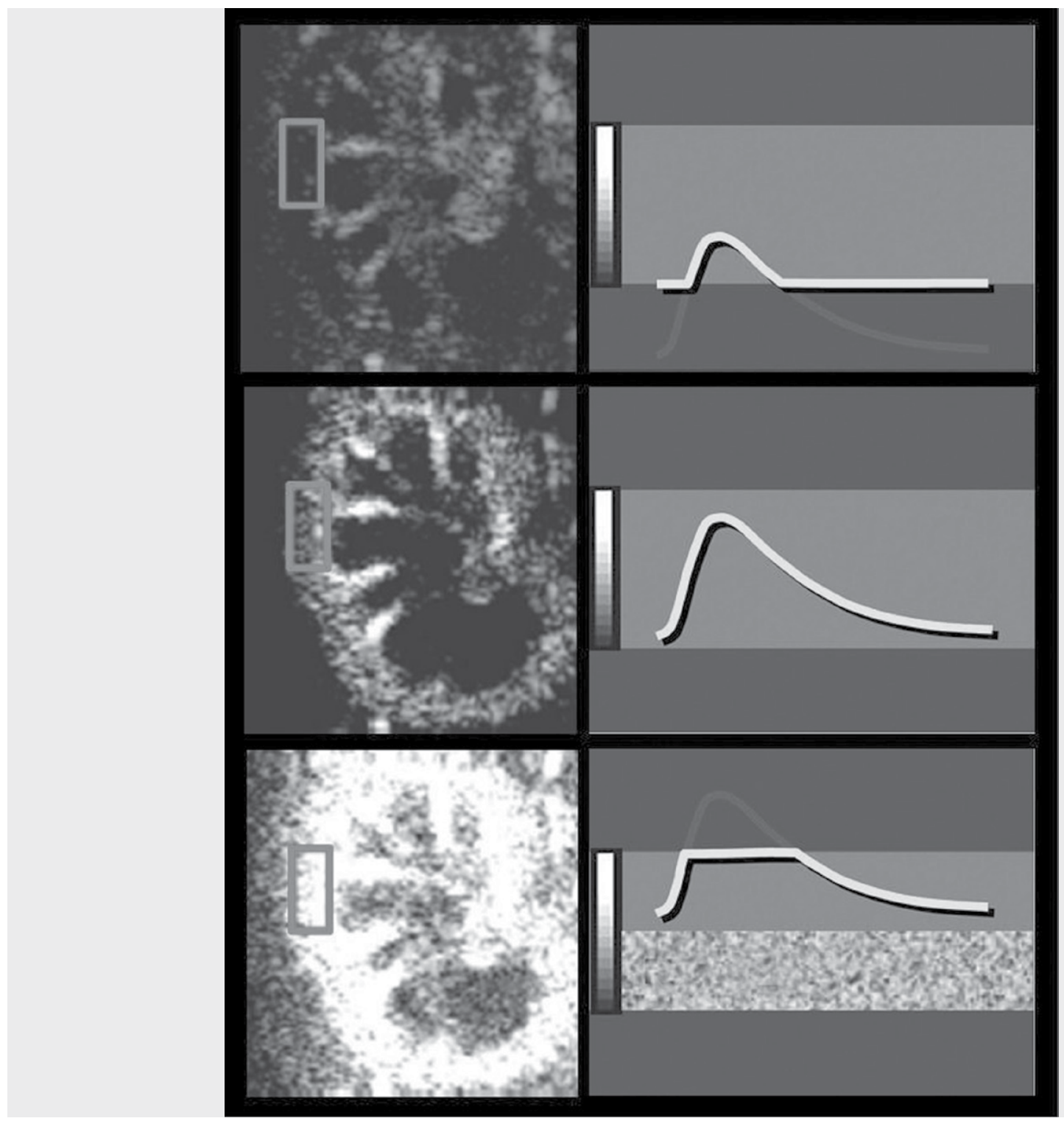

- Fig. 4 Low gain setting results in underestimation of the microbubbles located in the microcirculation (a). The proper gain setting results in a correct display of microbubbles in both micro- and macrovessels (b). High gain results in signal oversaturation and the image is too bright making the distinction between macro and micro-vasculature more difficult (c).

of signal intensities to be displayed. A wide dynamic range increases the number of signal levels ("grey levels"), allowing for better differentiation between different degrees of enhancement. A small dynamic range will decrease the number of "colours" in the image and increases visual contrast but can limit the differentiation between areas of variable enhancement. For example, in a vascular metastatic lesion there is often a rim of increased signal surrounding the lesion. If the dynamic range is set too narrow - the rim will be displayed in the same "colour" as the lesion and the increased signal in this area may not be appreciated. Lowering the dynamic range will let the vessels stand out brighter, but it should not be too low that the gray or colorized bubble image suffers in contrast resolution. With a large dynamic range, the increased rim of signal can be better identified.
For visualisation of lesions with low perfusion, a narrow dynamic range is preferred. For perfusion quantification studies, a wide dynamic range should be used to avoid signal saturation. It should be noted that reducing the dynamic range can increase the apparent difference between lesional and parenchymal enhancement. If acquiring a series of cases whose appearances are to be compared, it may be advantageous to keep the dynamic range and other postprocessing settings constant.

\section{Frame rate}

A frame rate $\geq 10 \mathrm{~Hz}$ is recommended for adequate visualization and recording of the wash-in patterns when characterizing focal liver lesions (FLL). The contrast wash-in may only be visualized for about a second in some highly vascularized lesions and is best appreciated using retrospective frame-by-frame cine review. Moreo- 
ver, a high frame rate is also important during sweeps of the liver to detect lesions so as to avoid skipping significant regions of the organ [40]. However, increased frame rates can augment bubble destruction, and decreasing the frame rate in the late vascular phases will prolong the enhancement time.

\section{Acoustic amplitude (AA) and mechanical index (MI)}

The Acoustic Pressure Amplitude $(P)$ refers to the peak negative amplitude of the ultrasound pulse used for imaging. It is measured in $\mathrm{Pa}$ and is used in the calculation of the Mechanical Index (MI). The $\mathrm{Ml}$ is an estimate of the maximum peak negative acoustic pressure in the tissue within the acoustic field scaled by the square root of the center frequency. $\mathrm{MI}$ is related to the likelihood of cavitation and the US Food and Drug Administration (FDA) limits the maximum MI to a value of 1.9 [when $\mathrm{P}$ is measured in MPa and frequency in $\mathrm{MHz}$. In addition to the MI, which refers to the highest value in the acoustic field, some manufacturers also estimate and display the $\mathrm{Ml}$ at the focus zone or the percentage of maximum acoustic power that allows finer tuning of the acoustic energy delivered [40]. It is important to note that there is a direct linear relationship between $\mathrm{P}$ and the $\mathrm{MI}$ (within linear acoustics). Choosing the appropriate MI is important for effective CEUS because as summarized in [40] this parameter affects several processes relevant to image quality and microbubble behaviour. These parameters are listed below and discussed in more detail later.

- The degree and rate of microbubble destruction.

- The depth of ultrasound beam penetration.

- The ability to separate signals scattered from background tissue versus those scattered by microbubbles, since tissue scattering is linear at low amplitudes (low MIs) while microbubble scattering is non-linear at all amplitudes.

While the MI on-screen labelling is mandated by the FDA, manufacturers nonetheless use different calculations to arrive at this number. In practice, for contrast imaging, the number is not transferrable between machines. Thus, an optimal MI for a particular patient scanned with one machine may not be the same as for the same patient scanned with another.

\section{Contrast Enhanced Ultrasound}

\section{Ultrasound contrast agents (UCA)}

UCAs consist of gas microbubbles coated with a shell, usually comprised of phospholipid or albumin. Microbubbles act as resonant scatterers, increasing the backscatter signal by up to $30 \mathrm{~dB}$, and producing echoes with characteristic harmonics. All UCAs are blood pool agents, but - as discussed earlier - some are pure blood pool agents while others are phagocytosed by reticulo-endothelial cells, causing their appearance to differ in the liver-specific late phases.

\section{No need for laboratory tests prior to CEUS}

UCAs are extremely safe with low incidence of side effects [46] and no cardio-, hepato- or nephrotoxic effects. Therefore, it is not necessary to perform laboratory tests to assess liver or kidney function prior to their administration [47].

\section{Pre-contrast examination}

The pre-contrast examination preparations include the identification of the best position of the patient, the identification of the target lesion and the optimal scan plane along the axis of the respiratory movements (usually longitudinal) to minimize out-of-plane motion from respiration. The optimal patient breathing position is determined and practiced with the patient prior to the contrast injection. Quiet breathing and breath suspension in neutral are preferred over breath hold in full inspiration or expiration.

\section{Catheter}

The best position of the patient should be determined during the pre-contrast examination and this may affect which arm is chosen for injection. In most circumstances, the cannula should be inserted in the left arm, preferably the antecubital vein, to avoid interaction of the injector with the right-sided examiner. Be aware of other important influencing factors, e. g., avoid the side of breast (or axillary) surgery to minimise the risk of worsening lymphedema.

Ideally, the diameter of the venous line should be 20 gauge or larger to minimize microbubble destruction during passage through the cannula, with its length as short as possible. Central line and port systems can be used as long as there is no filter requiring a high injection pressure. Their use will shorten contrast arrival time [48].

In cases of difficult venous cannulation, US guided needle placement using a high frequency linear probe is recommended.

The catheter can be removed after exclusion of any kind of pseudoanaphylactic, e. g., 15 min after contrast injection.

\section{3-way stopcock}

A three-way stopcock may be valuable, especially if multiple injections are anticipated, as this facilitates sequential administration of the contrast material and then the saline flush, without removal of either syringe.

\section{Injection}

The injection bolus for SonoVue ${ }^{\mathrm{TM}}$ is given at about $1-2 \mathrm{ml} / \mathrm{s}$. Avoid high pressure (risk of microbubble destruction). Immediately after injecting the contrast agent, a (5-) $10 \mathrm{ml}$ saline bolus should be given to flush the line at about $2 \mathrm{ml} / \mathrm{s}[4,38]$.

\section{Central venous line and "port"}

Central venous lines and ports may be used for CEUS if necessary if safety and aseptic requirements are met, but their use is discouraged if a peripheral vein can be accessed. Injecting UCAs through a central venous line or port requires a higher level of expertise to ensure a successful injection. Bubble disruption may also be increased necessitating a dose increase. The use of a central venous line requires a 3-way stopcock. Contrast arrival times are usually significantly shorter in case of a central-venous administration, a fact which might favour starting the timer earlier, at the beginning of the contrast injection.

\section{Contrast agent dose}

Using the optimal dose is important. Too high a contrast agent dose results in artefacts, particularly in the early phases of enhancement. 
These include acoustic shadowing, over-enhancement of small structures and signal saturation, which is also detrimental for quantification. On the other hand, too low a dose causes the concentration of microbubbles to be subdiagnostic in the late phase, challenging the detection of wash out. If the liver washes out early, the dose was probably too low or inherent significant intrahepatic shunting may prevent a longer enhancement time. Again, it is important to evaluate the status of the liver as being healthy or diseased. In difficult cases, a second (higher) dose may be administered, with no or only limited scanning in the early phases [40] to reduce bubble destruction. The exact dose depends on the UCA, ultrasound equipment (software version, transducer), type of examination, organ and target lesion, size and age of the patient and other factors.

For SonoVue TM/Lumason ${ }^{\mathrm{TM}}, 2.4 \mathrm{ml}$ (1/2 vial) is recommended for most indications in the liver (detection, characterisation) but many investigators are now using $1.2 \mathrm{ml}$ (this topic has been controversially discussed with co-authors and the reviewers).

For SonoVue ${ }^{\mathrm{TM}} /$ Lumason $^{\mathrm{TM}}, 2.4 \mathrm{ml}$ (1/2 vial) is the standard dose for most indications in the pancreas, spleen and kidney. For the pancreas, spleen and kidney, $1.2 \mathrm{ml}$ often suffices. Depending on scanning conditions and depth of the lesion (organ) even lower doses can be used. For high frequency applications $4.8 \mathrm{ml}$ is suggested. In particular, endoscopic ultrasound usually requires the complete vial of $4.8 \mathrm{ml}$ [51-53]. For the extravascular (intraluminal) use only few drops diluted in normal saline solution are necessary. For Definity ${ }^{\mathrm{TM}}$ and Optison ${ }^{\mathrm{TM}}$ a standard dose is $0.2-0.3 \mathrm{ml}$ for an adult. For Sonazoid ${ }^{\mathrm{TM}}$ a dose of $0.015 \mathrm{ml} / \mathrm{kg}$ (e. g., $0.5-1.0 \mathrm{ml}$ ) of the reconstituted suspension is recommended.

\section{Repeated injection}

Multiple injections of UCA are variably indicated and influenced mainly by the manufacturing of the different solutions and the volume needed to provide good visualization of the liver and a focal liver mass. SonoVue ${ }^{\mathrm{TM}} /$ Lumason $^{\mathrm{TM}}$, supplied in a $4.8 \mathrm{ml}$ aliquot may allow for two or possibly three or four injections per vial, whereas Definity ${ }^{\mathrm{TM}}$, supplied in a $1.3 \mathrm{ml}$ vial, which expands to $1.8 \mathrm{ml}$ in solution may allow for multiple injections as needed (easily 6 or 7 ) as a standard bolus would generally be only $0.2-0.3 \mathrm{ml}^{\text {. For Sonazoid }}{ }^{\mathrm{TM}}$ supplied in a $2 \mathrm{ml}$ vial, a dose of $0.5-1.0 \mathrm{ml}$ per injection $(0.015 \mathrm{ml} /$ $\mathrm{kg}$ ) is recommended.

Repeated injection may occur in the following circumstances:

- There are additional nodules or observations, which require characterization.

- The initial injection may not provide the full answer to the characterization of a lesion, requiring a second injection to allow for assessment of missing information.

- A wash-out region may be identified on sweeps of the liver in either the PVP or the LP. Even if a corresponding nodule is not visible on the conventional B-mode images, arterial phase enhancement in the wash-out region can be characterized by re-injecting contrast material while keeping that region in the field of view.

For the first two indications above, the examiner usually should wait before reinjecting until the bubbles from the previous injection have disappeared or least greatly reduced, which usually requires 10 to 15 min for SonoVue ${ }^{\mathrm{TM}} /$ Lumason $^{\mathrm{TM}}$ and Definity ${ }^{\mathrm{TM}}$ also depending on patient age and constitution. The waiting period is much longer for Sonazoid ${ }^{\mathrm{TM}}$, the disappearance of bubbles may take longer than one hour. To expedite bubble destruction and reduce the delay for re-injection, continuous scanning at high $\mathrm{MI}$, such as B-mode or colour Doppler can be performed including the heart and kidney. To assess arterial enhancement of a wash-out region that does not have a correlate on B-mode imaging, by comparison, the examiner should re-inject before bubbles have disappeared so as to maintain visibility of the wash-out region.

\section{Continuous Infusion}

Dynamic real-time characterization of focal liver masses with CEUS is best performed with a bolus technique. However, measurement of blood flow parameters for assessment of oncologic response to therapy is also possible with an infusion and the destruction-replenishment technique. The agent is, depending on the contrast agent, suspended in saline or other media and intravenously infused with controlled pressure, to avoid bubble destruction and at a constant rate to permit prolonged scanning. This technique provides a steady-state bubble concentration which can be used with the burst and replenish mode (manoeuvre) to generate multiple measurements. For Definity ${ }^{\mathrm{TM}}$, where bubble flotation is not usually an issue, the agent can be mixed in a $50 \mathrm{ml}$ saline bag. For Sono$V_{u e}{ }^{\mathrm{TM}}$, a dedicated infusion pump is recommended. For more details see the EFSUMB guidelines [11].

\section{Contrast timer}

All ultrasound scanners must have a visible timer. This timer should be started at the time of the beginning of the UCA injection for SonoVue ${ }^{\mathrm{TM}} /$ Lumason $^{\mathrm{TM}}$. With Definity $^{\mathrm{TM}}$, no CA enters the body prior to the flush. The authors controversially discussed when to start the timer. Most (but not all) of the group agreed that the timer should be started at the beginning of the contrast injection. The application via a central venous line with much shorter arrival time is a good reason for this. It should be noted that in special situations (e. g., right heart insufficiency) contrast phases may appear at unusual time points including potential initial retrograde inflow via the liver vein.

\section{Artefacts}

\section{Nonlinear propagation artefact}

A pseudo-enhancement of tissue has been reported in the literature where targets in tissue are registered as bubble signals [5456]. It has been suggested that the artefact is the result of nonlinear propagation of ultrasound in tissue perfused with a high concentration of microbubbles. The presence of microbubbles effectively increases the nonlinear coefficient of the "bulk" medium causing some nonlinear propagation to occur despite using low MI to prevent this phenomenon. Thus, when bright targets are encountered in the ultrasound path they produce echoes with nonlinear components caused by nonlinear propagation rather than by microbubble scattering. This pseudo-enhancement can be differentiated from true bubble signals by recognizing their non-physiologic nature, or by comparing the bubble image with the tissue image and identifying the same bright targets in both images. A 
way to reduce this artefact is to avoid high doses of contrast agents, and/or avoid having a large vessel in the ultrasound path proximal to the area/lesion of interest. In clinical practice, this is problematic most often in the follow up of treatment sites following ablative therapy for liver tumours [57]. A bright echogenic focus within the treatment zone may show linear artefact which may be mistaken for residual or recurrent tumour. Clues to the correct interpretation include lack of arterial phase enhancement dynamics, when a real tumour would be perfused, and increasing pseudoenhancement in the portal and delayed phases attributed to the nonlinear artefact as bubbles fill the portal system.

\section{How to avoid artefacts?}

The ideal is to find a good compromise between the contrast agent dose and the equipment-specific settings. The Ml and the transmit frequency ("penetration mode") play a crucial role here. This balances the signal intensity and penetration on the one hand, and the stability of the microbubbles on the other hand. A higher MI results in a stronger signal and better penetration but also increased destruction of the microbubbles. The contrast agent dose balances the contrast enhancement intensity in the early phase (prevention of the over saturation of structures with shadowing) and the contrast enhancement duration (sufficient contrast agent concentration in the late phase).

The CEUS "circle of disaster" is characterized by the following criteria: Microbubble destruction $\rightarrow$ increase in contrast agent dose $\rightarrow$ attenuation (shadowing) $\rightarrow$ higher mechanical index $\rightarrow$ additional microbubble destruction $[40,41,58]$.

In conclusion, if the $\mathrm{MI}$ is too high, an increase of UCA dose to compensate may cause additional attenuation. Further influencing factors are gain, dynamic range, frame rate, transmission frequency, and equipment software [40]. Most often, the default settings on the machine provide an excellent starting point for beginning CEUS studies of the liver. For more details on CEUS artefacts we refer to the current literature [40, 55-59].

\section{Prolonged Liver Enhancement}

Prolonged innocuous liver enhancement after the bolus injection of microbubble contrast agents appears as a heterogeneous enhancement in the liver during the performance of the CEUS examination, often beginning at around $2 \mathrm{~min}$ and lasting up to $5 \mathrm{~h}$ after contrast injection on both $\mathrm{B}$-mode and contrast-specific modes. It is not destroyed by conventional B-mode imaging. The enhanced signals can also be observed in the portal and superior mesenteric veins, though not in the systemic circulation [60]. It is similar in appearance to the US finding of free portal venous gas.

\section{Safety of CEUS}

As mentioned earlier, UCAs are safe with a very low incidence of side effects. As there are no cardio-, hepato-, or nephro-toxic effects, it is not necessary to perform laboratory checks to assess liver, renal or thyroid function before administration. The incidence of severe adverse events is lower than with current X-ray contrast agents and is comparable to those encountered with MR contrast agents. Life-threatening anaphylactic reactions in abdominal applications have been reported with a rate of $0.001 \%$, with no death in a series of $>23,000$ abdominal patients [46]. Further studies have reproduced this very low adverse event rate $[61,62]$. Nonetheless, investigators should be trained in resuscitation and have the appropriate facilities available to react in cases of adverse events $[4,38]$. In particular, each centre should be prepared with a crash chart and ability to treat anaphylactic shock if it occurs.

\section{Paediatric Patients and Newborns}

The use of CEUS in children, first reported in 2002, has been addressed in an EFSUMB position statement discussing the current status of CEUS and its further development in children [63]. Currently sulphur hexafluoride gas microbubbles (SonoVue ${ }^{\mathrm{TM}}$ /Lumason $^{\mathrm{TM}}$, Bracco SpA, Milan) has been approved in the United States by the Food and Drug Administration (FDA) as Lumason ${ }^{\mathrm{TM}}$ for characterising focal liver lesions in children ["Lumason is indicated for use with ultrasound of the liver in adult and pediatric patients to characterize focal liver lesions"] and vesico-ureteral reflux. In Europe, CEUS in children is mostly "off-label” use, except for a few indications including vesico-ureteral reflux [64]. The same is true for many drugs, which are used off-label in paediatric practice and the question of "off label use" has been widely discussed $[65,66]$. The recent approval of SonoVue ${ }^{\mathrm{TM}} /$ Lumason $^{\mathrm{TM}}$ for use in paediatrics in the United States is a welcome first step towards the acceptance of this technique in the non-ionising imaging of children [67].

\section{CEUS-guided Interventions}

CEUS-guided interventions for practical considerations is performed very much like a standard US guided procedure except that two injections of UCAs are used, one to plan the procedure and a second to guide the actual intervention. In some cases, a continuous infusion may be the better choice while in other cases the procedure may be performed without a second contrast injection if the perfusion conditions are adequately demonstrated with the first CEUS to allow for a standard ultrasound guided procedure. CEUS-guided biopsy has been reported to increase the diagnostic accuracy rate by up to $10 \%$ either by directing the biopsy towards contrast-enhanced - and thus viable - tissue inside the tumour and thereby avoiding sampling of necrotic material, or by identifying previously not-visualised lesions more accessible for biopsy [4, 6872]. Furthermore, CEUS may visualise active bleeding, hemobilia or segmental liver infarction.

CEUS is also helpful in performing and follow-up for radiofrequency ablation or cryotherapy for hepatic and renal masses $[37,73,74]$. CEUS allows evaluation of the extent of the ablated zone at the end of the procedure. If residual tumour is identified, the ablation can be extended after repositioning the needle to the residual tumour using CEUS guidance. On follow-up studies, CEUS is able to identify - immediately following treatment - small amounts of residual tumour, which can be too small or too soon to detect with CECT or CTMRI $[75,76]$. 


\section{Extravascular, Intracavitary}

Extravascular (intracavitary) CEUS (EV-CEUS) is used for imaging physiological and non-physiological body cavities. Physiological cavities include the peritoneal cavity, pleural cavity, biliary tract, gastrointestinal tract, urinary tract, etc. and pathological cavities include abscesses, cysts, diverticula, etc. $[68,77]$. The UCA is given through a needle or catheter, for instance, at cholangiography or nephrostomy. However, UCAs can also be given orally or as an enema for imaging the upper and lower gastrointestinal tract $[78,79]$.

The following clinical applications of EV-CEUS have been described in case studies: percutaneous nephrostomy [80], biliary tract imaging via percutaneous transhepatic cholangiography and drainage (PTCD) [81], abscess drainage [82], swallow CEUS for imaging Zenker's diverticulum, voiding vesicoureteral reflux sonography [83, 84], salivary gland duct imaging [85], contrast-enhanced hysterosalpingo-sonography (CE-HyCoSy [86], biliary tract imaging via endoscopic retrograde cholangiography (ERCP) [87] and fistula imaging [88].

The transducer used in extravascular CEUS is the same as that used in conventional US. SonoVue ${ }^{\mathrm{TM}}$ is currently the most often used UCA for VUR [89] though it is not licensed for other extravascular indications of CEUS. To date, no standard dosage of UCA has been established for extravascular CEUS. The reported range is $0.1 \mathrm{ml}-1 \mathrm{ml}$ SonoVue ${ }^{\mathrm{TM}}$ (most commonly just a few drops) diluted in $50 \mathrm{ml}$ or more of $0.9 \%$ saline. A higher content of SonoVue ${ }^{\mathrm{TM}}$ may be needed for high frequency US probes [68]. Compared with X-ray contrast techniques, EV-CEUS does not require exposure to ionizing radiation and can be performed at the bedside.

\section{Education, Qualification}

The World Health Organization (WHO) estimates that $2 / 3$ of the world's population lacks access to medical imaging [90]. Ultrasound (US) with CEUS may provide a way forwards. Investigators and clinicians wishing to perform CEUS examinations should gain experience by observing contrast studies performed by experts in the field [91]. The diagnostic performance of CEUS is correlated with the observer's level of experience [58, 92]. The examiner should also verify that his or her equipment is optimized for contrast examination and that the volume and diversity of cases will suffice to maintain skills. Practitioners need to be competent in the intravenous administration of contrast agents, be familiar with contraindications and be able to manage any possible adverse effects within the medical and legal framework of their country $[4,38]$. We refer to the educational activities of the collaborating societies of this paper, the World Federation of Ultrasound in Medicine and Biology (WFUMB) [9, 23, 93-102], the European Federation of Societies for Ultrasound in Medicine and Biology (EFSUMB) $[1,3,4,11,37,38,49,50,74,79,103-119]$ and the CEUS LI-RADS Working Group for Liver Imaging Reporting and Data System (LIRADS () [34-36, 120-124].

\section{Conclusion}

High-quality performance of CEUS is experience-dependent and requires regular use and understanding of the relevant physics, technical adjustments and contrast media variability. Each individual case requires detailed analysis of the enhancement patterns in all vascular and post-vascular phases. Despite the regulatory and practice obstacles for the use of UCAs for CEUS, the evidence indicates that CEUS can provide unique and accurate diagnostic information, in many cases also comparable and sometimes superior to the performance of CT and MRI [125-127].

\section{Acknowledgement}

We were all saddened by the news of David Cosgrove's death in May 2017 following a gallant battle with cancer. David Cosgrove was an esteemed teacher, prominent researcher and a good friend. He will be missed by all. We express our sincere condolences.

\section{Conflict of Interest}

Some authors declare conflicts of interest, which are available by the publisher and as supplemetary file.

\section{References}

[1] Albrecht T, Blomley M, Bolondi L, Claudon M, Correas JM, Cosgrove $D$, Greiner $L$ et al. Guidelines for the use of contrast agents in ultrasound. January 2004. Ultraschall Med. 2004; 25: 249-256

[2] Claudon M, Cosgrove D, Albrecht T, Bolondi L, Bosio M, Calliada F, Correas JM et al. Guidelines and good clinical practice recommendations for contrast enhanced ultrasound (CEUS) - Update 2008. Ultraschall Med. 2008; 29: 28-44

[3] Piscaglia F, Nolsoe C, Dietrich CF, Cosgrove DO, Gilja OH, Bachmann $\mathrm{NM}$, Albrecht T et al. The EFSUMB guidelines and recommendations on the clinical practice of contrast enhanced ultrasound (CEUS): Update 2011 on non-hepatic applications. Ultraschall Med. 2012; 33: 33-59

[4] Claudon M, Dietrich CF, Choi BI, Cosgrove DO, Kudo M, Nolsoe CP, Piscaglia F et al. Guidelines and good clinical practice recommendations for contrast enhanced ultrasound (CEUS) in the liver-update 2012: a WFUMB-EFSUMB initiative in cooperation with representatives of AFSUMB, AIUM, ASUM, FLAUS and ICUS. Ultraschall Med 2013; 34: 11-29

[5] Claudon M, Dietrich CF, Choi BI, Cosgrove DO, Kudo M, Nolsoe CP, Piscaglia $\mathrm{F}$ et al. Guidelines and good clinical practice recommendations for Contrast Enhanced Ultrasound (CEUS) in the liver - update 2012: A WFUMB-EFSUMB initiative in cooperation with representatives of AFSUMB, AIUM, ASUM, FLAUS and ICUS. Ultrasound Med Biol 2013; 39: 187-210

[6] Dietrich CF, Ignee A, Trojan J, Fellbaum C, Schuessler G. Improved characterisation of histologically proven liver tumours by contrast enhanced ultrasonography during the portal venous and specific late phase of SHU 508 A. Gut 2004; 53: 401-405

[7] Dietrich CF, Schuessler G, Trojan J, Fellbaum C, Ignee A. Differentiation of focal nodular hyperplasia and hepatocellular adenoma by contrast-enhanced ultrasound. Br.J.Radiol. 2005; 78: 704-707

[8] Dietrich CF. Signalverstärkte Lebersonographie zur verbesserten Detektion und Charakterisierung von Leberraumforderungen. Dt Aerzteblatt 2002; 24: 7

[9] Dietrich CF. [3D real time contrast enhanced ultrasonography,a new technique]. Rofo 2002; 174: 160-163 
[10] Dietrich CF, Brunner V, Braden B, Zeuzem S, Caspary WF. Erste Erfahrungen mit einem neuen Signalverstärker bei der Untersuchung der Leber. Ultraschall Med 1998; 19 :

[11] Dietrich CF, Averkiou MA, Correas JM, Lassau N, Leen E, Piscaglia F. An EFSUMB introduction into Dynamic Contrast-Enhanced Ultrasound (DCE-US) for quantification of tumour perfusion. Ultraschall Med 2012; 33: 344-351

[12] Ignee A, Jedrejczyk M, Schuessler G, Jakubowski W, Dietrich CF. Quantitative contrast enhanced ultrasound of the liver for time intensity curves-Reliability and potential sources of errors. Eur J Radiol 2010; 73: 153-158

[13] Lassau N, Cosgrove D, Armand JP. Early evaluation of targeted drugs using dynamic contrast-enhanced ultrasonography for personalized medicine. Future Oncol 2012; 8: 1215-1218

[14] Lassau N, Koscielny S, Chami L, Chebil M, Benatsou B, Roche A, Ducreux $\mathrm{M}$ et al. Advanced hepatocellular carcinoma: early evaluation of response to bevacizumab therapy at dynamic contrast-enhanced US with quantification--preliminary results. Radiology 2011; 258: 291-300

[15] Lassau N, Koscielny S, Albiges L, Chami L, Benatsou B, Chebil M, Roche $A$ et al. Metastatic renal cell carcinoma treated with sunitinib: early evaluation of treatment response using dynamic contrast-enhanced ultrasonography. Clin Cancer Res 2010; 16: 1216-1225

[16] Frampas E, Lassau N, Zappa M, Vullierme MP, Koscielny S, Vilgrain V. Advanced Hepatocellular Carcinoma: early evaluation of response to targeted therapy and prognostic value of Perfusion CT and Dynamic Contrast Enhanced-Ultrasound. Preliminary results. Eur J Radiol 2013; 82: e205-e211

[17] Williams R, Hudson JM, Lloyd BA, Sureshkumar AR, Lueck G, Milot L, Atri $M$ et al. Dynamic microbubble contrast-enhanced US to measure tumor response to targeted therapy: A proposed clinical protocol with results from renal cell carcinoma patients receiving antiangiogenic therapy. Radiology 2011; 260: 581-590

[18] Leen E, Averkiou M, Arditi M, Burns P, Bokor D, Gauthier T, Kono Y et al. Dynamic contrast enhanced ultrasound assessment of the vascular effects of novel therapeutics in early stage trials. Eur Radiol 2012; 22: $1442-1450$

[19] Serra C, Menozzi G, Labate AM, Giangregorio F, Gionchetti P, Beltrami $M$, Robotti $D$ et al. Ultrasound assessment of vascularization of the thickened terminal ileum wall in Crohn's disease patients using a low-mechanical index real-time scanning technique with a second generation ultrasound contrast agent. Eur J Radiol 2007; 62: 114-121

[20] Atkinson NS, Bryant RV, Dong Y, Maaser C, Kucharzik T, Maconi G, Asthana AK et al. WFUMB Position Paper. Learning gastrointestinal ultrasound: Theory and practice. Ultrasound Med Biol 2016; 42: 2732-2742

[21] Nylund K, Maconi G, Hollerweger A, Ripolles T, Pallotta N, Higginson $A$, Serra $C$ et al. EFSUMB recommendations and guidelines for gastrointestinal ultrasound. Ultraschall Med 2017; 38: e1-e15

[22] Nylund K, Maconi G, Hollerweger A, Ripolles T, Pallotta N, Higginson A, Serra $C$ et al. EFSUMB recommendations and guidelines for gastrointestinal ultrasound. Ultraschall Med 2017; 38: 273-284

[23] Hocke M, Dietrich CF. New technology-combined use of 3D contrast enhanced endoscopic ultrasound techniques. Ultraschall Med 2011; 32: $317-318$

[24] Hocke M, Ignee A, Dietrich CF. Three-dimensional contrast-enhanced endoscopic ultrasound for the diagnosis of autoimmune pancreatitis. Endoscopy 2011; 43: (Suppl 2): UCTN E381-E382

[25] Fusaroli P, Saftoiu A, Dietrich CF. Contrast-enhanced endoscopic ultrasound: Why do we need it? A foreword. Endosc Ultrasound 2016

[26] Dietrich CF, Sharma M, Hocke M. Contrast-enhanced endoscopic ultrasound. Endosc Ultrasound 2012; 1: 130-136
[27] Solbiati L, Tonolini M, Cova L, Goldberg SN. The role of contrast-enhanced ultrasound in the detection of focal liver leasions. Eur Radiol 2001; 11: (Suppl 3): E15-E26

[28] D'Onofrio M, Martone E, Faccioli N, Zamboni G, Malago R, Mucelli RP. Focal liver lesions: Sinusoidal phase of CEUS. Abdom Imaging 2006; 31: 529-536

[29] Strobel D, Seitz K, Blank W, Schuler A, Dietrich C, von Herbay A, Friedrich-Rust $\mathrm{M}$ et al. Contrast-enhanced ultrasound for the characterization of focal liver lesions-diagnostic accuracy in clinical practice (DEGUM multicenter trial). Ultraschall Med 2008; 29: 499-505

[30] Bernatik T, Seitz K, Blank W, Schuler A, Dietrich CF, Strobel D. Unclear focal liver lesions in contrast-enhanced ultrasonography-lessons to be learned from the DEGUM multicenter study for the characterization of liver tumors. Ultraschall Med 2010; 31: 577-581

[31] Seitz K, Greis C, Schuler A, Bernatik T, Blank W, Dietrich CF, Strobel D. Frequency of tumor entities among liver tumors of unclear etiology initially detected by sonography in the noncirrhotic or cirrhotic livers of 1349 patients. Results of the DEGUM multicenter study. Ultraschall Med 2011; 32: 598-603

[32] Strobel D, Bernatik T, Blank W, Schuler A, Greis C, Dietrich CF, Seitz K. Diagnostic accuracy of CEUS in the differential diagnosis of small $(</=20 \mathrm{~mm})$ and subcentimetric $(</=10 \mathrm{~mm})$ focal liver lesions in comparison with histology. Results of the DEGUM multicenter trial. Ultraschall Med 2011; 32: 593-597

[33] Jo PC, Jang H], Burns PN, Burak KW, Kim TK, Wilson SR. Integration of Contrast-enhanced US into a Multimodality Approach to Imaging of Nodules in a Cirrhotic Liver: How I Do It. Radiology 2017; 282: 317-331

[34] Dietrich CF, Kono Y, DC Jang HJ, Kim TK, Piscaglia F, Sirlin CB et al Contrast-Enhanced Ultrasound: Liver Imaging Reporting and Data System (CEUS LI-RADS). In. http://www.solutionsincontrastimaging. com/ 2016;

[35] Kono Y, Lyshchik A, Cosgrove D, Dietrich CF, Jang HJ, Kim TK, Piscaglia F et al. Contrast Enhanced Ultrasound (CEUS) Liver Imaging Reporting and Data System (LI-RADS(R)): The official version by the American College of Radiology (ACR). Ultraschall Med 2017; 38: 85-86

[36] Piscaglia F, Wilson SR, Lyshchik A, Cosgrove D, Dietrich CF, Jang H], Kim TK et al. American College of Radiology Contrast Enhanced Ultrasound Liver Imaging Reporting and Data System (CEUS LI-RADS) for the diagnosis of Hepatocellular Carcinoma: A pictorial essay. Ultraschall Med 2017

[37] Dietrich CF, Lorentzen T, Appelbaum L, Buscarini E, Cantisani V, Correas JM, Cui XW et al. EFSUMB Guidelines on Interventional Ultrasound (INVUS), Part III - Abdominal Treatment Procedures (Long Version). Ultraschall Med 2016; 37: E1-E32

[38] Claudon M, Dietrich CF, Choi BI, Cosgrove DO, Kudo M, Nolsoe CP, Piscaglia $\mathrm{F}$ et al. Guidelines and good clinical practice recommendations for Contrast Enhanced Ultrasound (CEUS) in the liver - update 2012: A WFUMB-EFSUMB initiative in cooperation with representatives of AFSUMB, AIUM, ASUM, FLAUS and ICUS. Ultrasound Med Biol 2013; 39: 187-210

[39] Kudo M. Defect Reperfusion Imaging with Sonazoid(R): A Breakthrough in Hepatocellular Carcinoma. Liver Cancer 2016; 5: 1-7

[40] Dietrich CF, Ignee A, Greis C, Cui XW, Schreiber-Dietrich DG, Hocke M. Artifacts and pitfalls in contrast-enhanced ultrasound of the liver. Ultraschall Med 2014; 35: 108-125 quiz 126-107

[41] Dietrich CF, Greis C. [How to perform contrast enhanced ultrasound]. Dtsch Med Wochenschr 2016; 141: 1019-1024 
[42] Lassau N, Bonastre J, Kind M, Vilgrain V, Lacroix J, Cuinet M, Taieb S et al. Validation of dynamic contrast-enhanced ultrasound in predicting outcomes of antiangiogenic therapy for solid tumors: The French multicenter support for innovative and expensive techniques study. Invest Radiol 2014; 49: 794-800

[43] O'Connor JP, Aboagye EO, Adams JE, Aerts H], Barrington SF, Beer A], Boellaard $R$ et al. Imaging biomarker roadmap for cancer studies. Nat Rev Clin Oncol 2017; 14: 169-186

[44] Averkiou M, Lampaskis M, Kyriakopoulou K, Skarlos D, Klouvas G, Strouthos C, Leen E. Quantification of tumor microvascularity with respiratory gated contrast enhanced ultrasound for monitoring therapy. Ultrasound Med Biol 2010; 36: 68-77

[45] Lassau N, Chapotot L, Benatsou B, Vilgrain V, Kind M, Lacroix J, Cuinet $M$ et al. Standardization of dynamic contrast-enhanced ultrasound for the evaluation of antiangiogenic therapies: The French multicenter Support for Innovative and Expensive Techniques Study. Invest Radiol 2012; 47: 711-716

[46] Piscaglia F, Bolondi L.Italian Society for Ultrasound in M, Biology study group on ultrasound contrast $A$. The safety of Sonovue in abdominal applications: retrospective analysis of 23188 investigations. Ultrasound Med Biol 2006; 32: 1369-1375

[47] Appis AW, Tracy M], Feinstein SB. Update on the safety and efficacy of commercial ultrasound contrast agents in cardiac applications. Echo Res Pract 2015; 2: R55-R62

[48] Eisenbrey JR, Daecher A, Kramer MR, Forsberg F. Effects of Needle and catheter size on commercially available ultrasound contrast agents. J Ultrasound Med 2015; 34: 1961-1968

[49] Jenssen C, Brkljacic B, Hocke M, Ignee A, Piscaglia F, Radjina M, Sidhu PS et al. EFSUMB Guidelines on Interventional Ultrasound (INVUS), Part VI - Ultrasound-Guided Vascular Interventions. Ultraschall Med 2015

[50] Dietrich CF, Horn R, Morf S, Chiorean L, Dong Y, Cui XW, Atkinson N et al. US-guided peripheral vascular interventions, comments on the EFSUMB guidelines. Med Ultrason 2016; 18: 231-239

[51] Dietrich CF, Sahai AV, D'Onofrio M, Will U, Arcidiacono PG, Petrone MC, Hocke M et al. Differential diagnosis of small solid pancreatic lesions. Gastrointest Endosc 2016; 84: 933-940

[52] Ignee A, Atkinson NS, Schuessler G, Dietrich CF. Ultrasound contrast agents. Endosc Ultrasound 2016

[53] Ignee A, Jenssen C, Hocke M, Dong Y, Wang WP, Cui XW, Woenckhaus $M$ et al. Contrast-enhanced (endoscopic) ultrasound and endoscopic ultrasound elastography in gastrointestinal stromal tumors. Endosc Ultrasound 2017; 6: 55-60

[54] Yildiz YO, Eckersley RJ, Senior R, Lim AK, Cosgrove D, Tang MX. Correction of Non-Linear Propagation Artifact in Contrast-Enhanced Ultrasound Imaging of Carotid Arteries: Methods and in Vitro Evaluation. Ultrasound Med Biol 2015; 41: 1938-1947

[55] Renaud G, Bosch JG, Ten Kate GL, Shamdasani V, Entrekin R, de Jong $\mathrm{N}$, van der Steen AF. Counter-propagating wave interaction for contrast-enhanced ultrasound imaging. Phys Med Biol 2012; 57: L9-L18

[56] Thapar A, Shalhoub J, Averkiou M, Mannaris C, Davies AH, Leen EL. Dose-dependent artifact in the far wall of the carotid artery at dynamic contrast-enhanced US. Radiology 2012; 262: 672-679

[57] Yu H, Jang HJ, Kim TK, Khalili K, Williams R, Lueck G, Hudson J et al. Pseudoenhancement within the local ablation zone of hepatic tumors due to a nonlinear artifact on contrast-enhanced ultrasound. AJR Am J Roentgenol 2010; 194: 653-659

[58] Greis C. Technical aspects of contrast-enhanced ultrasound (CEUS) examinations: Tips and tricks. Clin Hemorheol Microcirc 2014; 58: 89-95

[59] Dietrich CF, Ignee A, Hocke M, Schreiber-Dietrich D, Greis C. Pitfalls and artefacts using contrast enhanced ultrasound. Z Gastroenterol 2011; 49: 350-356
[60] Cui XW, Ignee A, Hocke M, Seitz K, Schrade G, Dietrich CF. Prolonged heterogeneous liver enhancement on contrast-enhanced ultrasound. Ultraschall Med 2014; 35: 246-252

[61] Kusnetzky LL, Khalid A, Khumri TM, Moe TG, Jones PG, Main ML. Acute mortality in hospitalized patients undergoing echocardiography with and without an ultrasound contrast agent: Results in 18,671 consecutive studies. J Am Coll Cardiol 2008; 51: 1704-1706

[62] Main ML, Ryan AC, Davis TE, Albano MP, Kusnetzky LL, Hibberd M. Acute mortality in hospitalized patients undergoing echocardiography with and without an ultrasound contrast agent (multicenter registry results in 4,300,966 consecutive patients). Am J Cardiol 2008; 102: 1742-1746

[63] Sidhu PS, Cantisani V, Deganello A, Dietrich CF, Duran C, Franke D, Harkanyi Z et al. Role of Contrast-Enhanced Ultrasound (CEUS) in Paediatric Practice: An EFSUMB Position Statement. Ultraschall Med 2016

[64] Schreiber-Dietrich DG, Cui XW, Piscaglia F, Gilja OH, Dietrich CF. Contrast enhanced ultrasound in pediatric patients: A real challenge. Z Gastroenterol 2014; 52: 1178-1184

[65] Dietrich CF, Maurer M, Riemer-Hommel P. Challenges for the German Health Care System - Pharmaceuticals. Endheu 2014; 27: 45-53

[66] Esposito F, Di Serafino M, Sgambati P, Mercogliano F, Tarantino L, Vallone G, Oresta P. Ultrasound contrast media in paediatric patients: is it an off-label use? Regulatory requirements and radiologist's liability. Radiol Med 2012; 117: 148-159

[67] Chiorean L, Cui XW, Tannapfel A, Franke D, Stenzel M, Kosiak W, Schreiber-Dietrich $D$ et al. Benign liver tumors in pediatric patients - Review with emphasis on imaging features. World J Gastroenterol 2015; 21: 8541-8561

[68] Piscaglia F, Nolsoe C, Dietrich CF, Cosgrove DO, Gilja OH, Bachmann Nielsen M, Albrecht T et al. The EFSUMB Guidelines and Recommendations on the Clinical Practice of Contrast Enhanced Ultrasound (CEUS): update 2011 on non-hepatic applications. Ultraschall Med 2012; 33: 33-59

[69] Wu W, Chen MH, Yin SS, Yan K, Fan ZH, Yang W, Dai Y et al. The role of contrast-enhanced sonography of focal liver lesions before percutaneous biopsy. AJR Am J Roentgenol 2006; 187: 752-761

[70] Bang N, Bachmann Nielsen M, Vejborg I, Mellon Mogensen A. Clinical report: Contrast enhancement of tumor perfusion as a guidance for biopsy. Eur J Ultrasound 2000; 12: 159-161

[71] Sparchez Z, Radu P, Zaharia T, Kacso G, Grigorescu I, Botis G, Badea $R$. Usefulness of contrast enhanced ultrasound guidance in percutaneous biopsies of liver tumors. J Gastrointestin Liver Dis 2011; 20: 191-196

[72] Yoon SH, Lee KH, Kim SY, Kim YH, Kim JH, Lee SH, Kim TK. Real-time contrast-enhanced ultrasound-guided biopsy of focal hepatic lesions not localised on B-mode ultrasound. Eur Radiol 2010; 20: 2047-2056

[73] Lackey L 2nd, Peterson C, Barr RG. Contrast-enhanced ultrasound-guided radiofrequency ablation of renal tumors. Ultrasound $Q$ 2012; 28: 269-274

[74] Dietrich CF, Lorentzen T, Appelbaum L, Buscarini E, Cantisani V, Correas JM, Cui XW et al. EFSUMB Guidelines on Interventional Ultrasound (INVUS), Part III - Abdominal Treatment Procedures (Short Version). Ultraschall Med 2016; 37: 27-45

[75] Sanz E, Hevia V, Arias F, Fabuel J], Alvarez S, Rodriguez-Patron R, Gomez V et al. Contrast-enhanced ultrasound (CEUS): An excellent tool in the follow-up of small renal masses treated with cryoablation. Curr Urol Rep 2015; 16: 469

[76] Meloni MF, Bertolotto M, Alberzoni C, Lazzaroni S, Filice C, Livraghi T, Ferraioli G. Follow-up after percutaneous radiofrequency ablation of renal cell carcinoma: Contrast-enhanced sonography versus contrast-enhanced CT or MRI. AJR Am J Roentgenol 2008; 191 : $1233-1238$ 
[77] Ignee A, Schuessler G, Cui XW. Endocavernous Contrast-Enhanced Ultrasound - Different Applications, Literature Review and Future Perspectives. Ultraschall Med 2013; 34: 2-26

[78] Nylund K, Maconi G, Hollerweger A, Ripolles T, Pallotta N, Higginson $A$, Serra $C$ et al. EFSUMB Recommendations and Guidelines for Gastrointestinal Ultrasound - Part 1: Examination Techniques and Normal Findings (Long version). Ultraschall Med 2016

[79] Nylund K, Maconi G, Hollerweger A, Ripolles T, Pallotta N, Higginson A, Serra $C$ et al. EFSUMB Recommendations and Guidelines for Gastrointestinal Ultrasound - Part 1: Examination Techniques and Normal Findings (Short version). Ultraschall Med 2016

[80] Cui XW, Ignee A, Maros T, Straub B, Wen JG, Dietrich CF. Feasibility and Usefulness of Intra-Cavitary Contrast-Enhanced Ultrasound in Percutaneous Nephrostomy. Ultrasound Med Biol 2016; 42: 2180-2188

[81] Ignee A, Cui X, Schuessler G, Dietrich CF. Percutaneous transhepatic cholangiography and drainage using extravascular contrast enhanced ultrasound. Z Gastroenterol 2015; 53: 385-390

[82] Ignee A, Jenssen C, Cui XW, Schuessler G, Dietrich CF. Intracavitary contrast-enhanced ultrasound in abscess drainage-feasibility and clinical value. Scand J Gastroenterol 2016; 51: 41-47

[83] Darge K. Voiding urosonography with US contrast agents for the diagnosis of vesicoureteric reflux in children. II. Comparison with radiological examinations. Pediatr Radiol 2008; 38: 54-63 quiz 126-127

[84] Darge K. Voiding urosonography with ultrasound contrast agents for the diagnosis of vesicoureteric reflux in children. I. Procedure. Pediatr Radiol 2008; 38: 40-53

[85] Zengel P, Siedek V, Berghaus A, Clevert DA. Intraductally applied contrast-enhanced ultrasound (IA-CEUS) for improved visualization of obstructive diseases of the salivary glands, primary results. Clin Hemorheol Microcirc 2010; 45: 193-205

[86] Lanzani C, Savasi V, Leone FP, Ratti M, Ferrazzi E. Two-dimensional HyCoSy with contrast tuned imaging technology and a second-generation contrast media for the assessment of tubal patency in an infertility program. Fertil Steril 2009; 92: 1158-1161

[87] Zuber-Jerger I, Endlicher E, Scholmerich J, Klebl F. Endoscopic retrograde cholangiography with contrast ultrasonography. Endoscopy 2008; 40: (Suppl 2): E202

[88] Chew SS, Yang JL, Newstead GL, Douglas PR. Anal fistula: Levovist-enhanced endoanal ultrasound: a pilot study. Dis Colon Rectum 2003; 46: $377-384$

[89] Rosch T, Meining A, Fruhmorgen S, Zillinger C, Schusdziarra V, Hellerhoff K, Classen $M$ et al. A prospective comparison of the diagnostic accuracy of ERCP, MRCP, CT, and EUS in biliary strictures. Gastrointest Endosc 2002; 55: 870-876

[90] Hussain S. Welcome to the Journal of Global Radiology. Journal of Global Radiology 2015; 1: 1-2

[91] EFSUMB. Minimum training recommendations for the practice of medical ultrasound (European Federation of Societies for Ultrasound in Medicine Biology Practical Standards Committee). Ultraschall Med 2006; 27: 79-105

[92] Quaia E, Alaimo V, Baratella E, Pizzolato R, Cester G, Medeot A, Cova MA. Effect of observer experience in the differentiation between benign and malignant liver tumors after ultrasound contrast agent injection. J Ultrasound Med 2010; 29: 25-36

[93] Dong FJ, Xu JF, Du D, Jiao Y, Zhang L, Li M, Liu HY et al. 3D analysis is superior to 2D analysis for contrast-enhanced ultrasound in revealing vascularity in focal liver lesions - A retrospective analysis of 83 cases. Ultrasonics 2016; 70: 221-226

[94] Eisenbrey JR, Sridharan A, Machado P, Zhao H, Halldorsdottir VG, Dave JK, Liu JB et al. Three-dimensional subharmonic ultrasound imaging in vitro and in vivo. Academic Radiology 2012; 19: 732-739
[95] Feingold S, Gessner R, Guracar IM, Dayton PA. Quantitative volumetric perfusion mapping of the microvasculature using contrast ultrasound. Invest Radiol 2010; 45: 669-674

[96] Bamber J, Cosgrove D, Dietrich CF, Fromageau J, Bojunga J, Calliada F, Cantisani $V$ et al. EFSUMB guidelines and recommendations on the clinical use of ultrasound elastography. Part 1: Basic principles and technology. Ultraschall Med 2013; 34: 169-184

[97] Cosgrove D, Piscaglia F, Bamber J, Bojunga J, Correas JM, Gilja OH, Klauser AS et al. EFSUMB guidelines and recommendations on the clinical use of ultrasound elastography. Part 2: Clinical applications. Ultraschall Med 2013; 34: 238-253

[98] Cosgrove D, Barr R, Bojunga J, Cantisani V, Chammas MC, Dighe M, Vinayak $S$ et al. WFUMB Guidelines and Recommendations on the Clinical Use of Ultrasound Elastography: Part 4. Thyroid. Ultrasound Med Biol 2017; 43: 4-26

[99] Barr RG, Cosgrove D, Brock M, Cantisani V, Correas JM, Postema AW, Salomon $G$ et al. WFUMB Guidelines and Recommendations on the Clinical Use of Ultrasound Elastography: Part 5. Prostate. Ultrasound Med Biol 2017; 43: 27-48

[100] Dietrich CF, Muller T, Bojunga ], Dong Y, Mauri G, Radzina M, Dighe M et al. Statement and Recommendations on Interventional Ultrasound as a Thyroid Diagnostic and Treatment Procedure. Ultrasound Med Biol 2017

[101] Dighe M, Barr R, Bojunga J, Cantisani V, Chammas MC, Cosgrove D, Cui XW et al. Thyroid Ultrasound: State of the Art. Part 2 - Focal Thyroid Lesions. Med Ultrason 2017; 19: 195-210

[102] Dighe M, Barr R, Bojunga J, Cantisani V, Chammas MC, Cosgrove D, Cui XW et al. Thyroid Ultrasound: State of the Art Part 1 - Thyroid Ultrasound reporting and Diffuse Thyroid Diseases. Med Ultrason 2017; 19: 79-93

[103] Dietrich CF, Rudd L. The EFSUMB website, a guide for better understanding. Med Ultrason 2013; 15: 215-223

[104] Claudon M, Cosgrove D, Albrecht T, Bolondi L, Bosio M, Calliada F, Correas JM et al. Guidelines and good clinical practice recommendations for contrast enhanced ultrasound (CEUS) - update 2008. Ultraschall Med 2008; 29: 28-44

[105] Fusaroli P, Jenssen C, Hocke M, Burmester E, Buscarini E, Havre RF, Ignee $A$ et al. EFSUMB Guidelines on Interventional Ultrasound (INVUS), Part V - EUS-Guided Therapeutic Interventions (short version). Ultraschall Med 2016; 37: 412-420

[106] Jenssen C, Hocke M, Fusaroli P, Gilja OH, Buscarini E, Havre RF, Ignee A et al. EFSUMB Guidelines on Interventional Ultrasound (INVUS), Part IV - EUS-guided interventions: General Aspects and EUS-guided Sampling (Short Version). Ultraschall Med 2016; 37: 157-169

[107] Fusaroli P, Jenssen C, Hocke M, Burmester E, Buscarini E, Havre RF, Ignee $A$ et al. EFSUMB Guidelines on Interventional Ultrasound (INVUS), Part V. Ultraschall Med 2016; 37: 77-99

[108] Jenssen C, Hocke M, Fusaroli P, Gilja OH, Buscarini E, Havre RF, Ignee A et al. EFSUMB Guidelines on Interventional Ultrasound (INVUS), Part IV - EUS-guided Interventions: General aspects and EUS-guided sampling (Long Version). Ultraschall Med 2016; 37: E33-E76

[109] Lorentzen T, Nolsoe CP, Ewertsen C, Nielsen MB, Leen E, Havre RF, Gritzmann $\mathrm{N}$ et al. EFSUMB Guidelines on Interventional Ultrasound (INVUS), Part I. General Aspects (Short Version). Ultraschall Med 2015; 36: 464-472

[110] Lorentzen T, Nolsoe CP, Ewertsen C, Nielsen MB, Leen E, Havre RF, Gritzmann $\mathrm{N}$ et al. EFSUMB Guidelines on Interventional Ultrasound (INVUS), Part I. General Aspects (long Version). Ultraschall Med 2015; 36: E1-E14

[111] Jenssen C, Brkljacic B, Hocke M, Ignee A, Piscaglia F, Radzina M, Sidhu PS et al. EFSUMB Guidelines on Interventional Ultrasound (INVUS), Part VI. Ultraschall Med 2015 
[112] Fusaroli P, Jenssen C, Hocke M, Burmester E, Buscarini E, Havre RF, Ignee $A$ et al. EFSUMB Guidelines on Interventional Ultrasound (INVUS), Part V. Ultraschall Med 2015

[113] Sidhu PS, Brabrand K, Cantisani V, Correas JM, Cui XW, D'Onofrio M, Essig $M$ et al. EFSUMB Guidelines on Interventional Ultrasound (INVUS), Part II. Ultraschall Med 2015; 36: E15-E35

[114] Sidhu PS, Brabrand K, Cantisani V, Correas JM, Cui XW, D'Onofrio M, Essig $\mathrm{M}$ et al. EFSUMB Guidelines on Interventional Ultrasound (INVUS), Part II. Diagnostic Ultrasound-Guided Interventional Procedures (Long Version). Ultraschall Med 2015; 36: E15-E35

[115] Sidhu PS, Brabrand K, Cantisani V, Correas JM, Cui XW, D'Onofrio M, Essig $\mathrm{M}$ et al. EFSUMB Guidelines on Interventional Ultrasound (INVUS), Part II. Diagnostic Ultrasound-Guided Interventional Procedures (Short Version). Ultraschall Med 2015; 36: 566-580

[116] Dietrich CF. EFSUMB guidelines 2015 on interventional ultrasound. Med Ultrason 2015; 17: 521-527

[117] Lorentzen T, Nolsoe CP, Ewertsen C, Nielsen MB, Leen E, Havre RF, Gritzmann $\mathrm{N}$ et al. EFSUMB Guidelines on Interventional Ultrasound (INVUS), Part I. General Aspects (long Version). Ultraschall Med 2015; 36: E1-E14

[118] Lorentzen T, Nolsoe CP, Ewertsen C, Nielsen MB, Leen E, Havre RF, Gritzmann $\mathrm{N}$ et al. EFSUMB Guidelines on Interventional Ultrasound (INVUS), Part I. General Aspects (Short Version). Ultraschall Med 2015; 36: 464-472

[119] Dietrich CF, Lorentzen T, Sidhu PS, Jenssen C, Gilja OH, Piscaglia F. Efsumb. An Introduction to the EFSUMB Guidelines on Interventional Ultrasound (INVUS). Ultraschall Med 2015; 36: 460-463

[120] Piscaglia F, Kudo M, Han KH, Sirlin C. Diagnosis of Hepatocellular Carcinoma with Non-Invasive Imaging: A Plea for Worldwide Adoption of Standard and Precise Terminology for Describing Enhancement Criteria. Ultraschall Med 2017; 38: 9-11
[121] Lyshchik A, Kono Y, Dietrich CF, Jang H], Kim TK, Piscaglia F, Vezeridis $A$ et al. Contrast-enhanced ultrasound of the liver: Technical and lexicon recommendations from the ACR CEUS LI-RADS working group. Abdom Radiol (NY) 2017

[122] Kim TK, Noh SY, Wilson SR, Kono Y, Piscaglia F, Jang H], Lyshchik A et al. Contrast-enhanced ultrasound (CEUS) liver imaging reporting and data system (LI-RADS) 2017 - a review of important differences compared to the CT/MRI system. Clin Mol Hepatol 2017

[123] Wilson SR, Lyshchik A, Piscaglia F, Cosgrove D, Jang H], Sirlin C, Dietrich CF et al. CEUS LI-RADS: Algorithm, implementation, and key differences from CT/MRI. Abdom Radiol (NY) 2017

[124] Piscaglia F, Wilson SR, Lyshchik A, Cosgrove D, Dietrich CF, Jang H], Kim TK et al. American College of Radiology Contrast Enhanced Ultrasound Liver Imaging Reporting and Data System (CEUS LI-RADS) for the diagnosis of Hepatocellular Carcinoma: A pictorial essay. Ultraschall Med 2017; 38: 320-324

[125] Rafaelsen SR, Jakobsen A. Contrast-enhanced ultrasound vs multidetector-computed tomography for detecting liver metastases in colorectal cancer: A prospective, blinded, patient-by-patient analysis. Colorectal Dis 2011; 13: 420-425

[126] Bernatik T, Schuler A, Kunze G, Mauch M, Dietrich CF, Dirks K, Pachmann C et al. Benefit of Contrast-Enhanced Ultrasound (CEUS) in the Follow-Up Care of Patients with Colon Cancer: A Prospective Multicenter Study. Ultraschall Med 2015; 36: 590-593

[127] Dietrich CF, Kratzer W, Strobe D, Danse E, Fessl R, Bunk A, Vossas U et al. Assessment of metastatic liver disease in patients with primary extrahepatic tumors by contrast-enhanced sonography versus CT and MRI. World J Gastroenterol 2006; 12: 1699-1705 